\title{
Erratum zu: Rechtspopulismus oder rechter Verdruss? Eine empirische Analyse der Unterstützung der $A f D$ im Vorfeld der Bundestagswahl 2017
}

\author{
Markus Klein · Fabian Heckert • Yannic Peper
}

Online publiziert: 10 . Oktober 2018

(C) Springer Fachmedien Wiesbaden GmbH, ein Teil von Springer Nature 2018

\section{Erratum zu:}

Köln Z Soziol 2018

https://doi.org/10.1007/s11577-018-0564-4

Leider wurden zwei Fehler in Tab. 5 übersehen:

Der Koeffizient bei „Merkel ist vertrauenswürdig“ ist $-0,14$ statt 0,14 sowie bei „Geschlecht“ $-0,09$ statt 0,09 .

Die Autoren bitten diesen Fehler zu entschuldigen.

Die Online-Version des Originalartikels ist unter https://doi.org/10.1007/s11577-018-0564-4 zu finden.

M. Klein $(\bowtie) \cdot$ F. Heckert · Y. Peper

Institut für Politikwissenschaft, Leibniz Universität Hannover

Schneiderberg 50, 30167 Hannover, Deutschland

E-Mail: m.klein@ipw.uni-hannover.de

F. Heckert

E-Mail: fabian.heckert@stud.uni-hannover.de

Y. Peper

E-Mail: y.peper@ipw.uni-hannover.de 